longer suits the clinical situation. The British Dental Formulary reflects this in the small number of medicines available for dental prescription. The NHS Act does not set any limitations upon the number and variety of substances which the dental surgeon may administer to patients in the surgery or may order by private prescription (BNF 2010; 60: 6).

Homeopathic medicines are a valuable tool in the practitioner tool kit. They are not a cure all and should never be described as such. However, this therapeutic approach may be adopted when everything else has been addressed and found wanting. Very often a homeopathic prescription will assist the healing process when other interventions have not. A distinct though limited body of clinical research evidence supports the effectiveness of classical individualised homeopathy over and above placebo. ${ }^{1}$ There is a larger research evidence base to support the use of homotoxicological medicines as used in the EU, ie 106 studies relating to controlled human clinical trials, which have demonstrated that homeopathic medicines are superior to placebo. ${ }^{2}$

Homeopathically trained dentists are no different from any other kind of dentists - they are dentists in the first instance, homeopaths in the second. Homeopathic dental training in the UK is provided by the Faculty of Homeopathy with teaching centres at Glasgow, London and Bristol. A five year modular postgraduate course is available for those dentists wishing to extend their pharmaceutical knowledge.

Perhaps if Mr Shaw (an ethics lecturer not a practising dentist) would like to discuss with us the finer points of the appropriate uses of homeopathic medicine within dentistry, we would like to suggest he does this in person.

S. Farrer

By email

1. Linde K, Melchart D. Randomized controlled trials of individualized homeopathy: a state-of-the-art review. J Altern Complement Med 1998; 4: 371-388.

2. Homeopathy: the scientific proofs of efficacy. Milan: Guna S.r.l, 2002.

DOI: $10.1038 /$ sj.bdj.2011.246

\section{SEEK TO UNDERSTAND}

Sir, the Society of Homeopaths would like to point out a number of inaccuracies in D. Shaw's opinion article Unethical aspects of homeopathic dentistry (BDJ 2010; 209: 493-496).

Most importantly, the article wrongly states that the Society registers dentists. D. Shaw quotes widely from the Society's website, saying that the Society offers no specific information about dentistry which is 'unsurprising as it exists only to register dentists and provide a Code'. In actual fact, although the Society's register of professional homeopaths includes practitioners with backgrounds in law, banking, nursing, science, the armed forces and journalism, it is unsurprising that the website has no information on dentistry in as much as it does not register dentists.

This is only one example of a shocking lack of research on the part of D. Shaw, despite his own sweeping dismissal as flawed 'in one way or another' of all of the research evidence which suggests homeopathic medicine works over and above that of placebo.

The article fails to mention that by the end of 2009, 142 randomised controlled trials comparing homeopathy with placebo or conventional treatment had been published in peer-reviewed journals. In terms of statistically significant results, 74 of these trials were able to draw firm conclusions: 63 were positive for homeopathy and 11 were negative. ${ }^{1}$

D. Shaw further fails to mention that $75 \%$ of in vitro experiments have found that substances as dilute as homeopathic medicines have specific effects. ${ }^{2}$ For example, homeopathically-prepared thyroxine can slow down metamorphosis of tadpoles into frogs. ${ }^{3}$ These results were replicated by five separate laboratories in Austria and confirmed by the results of similar experiments carried out by an independent team in Brazil.4 The homeopathic thyroxine used was so highly diluted that you would not expect any molecules to be present. While more high quality research would be welcomed, it is simply untrue to say that there is no scientific evidence to support the efficacy of homeopathic medicine.

The Society is also concerned that D. Shaw makes serious allegations about practitioners of homeopathy. Firstly, he suggests that 'a routine feature of homeopaths marketing practices is to denigrate mainstream medicine'. He provides no evidence of this apart from the quote of Ben Goldacre, an anti-homeopathy campaigner.

Further, he states that homeopaths are unethical as, for there to be any benefit to homeopathy, patients must be 'deceived'. As already mentioned, there is a growing body of evidence showing the effectiveness of homeopathic medicine, including clinical outcome studies, the largest of which took place at the Bristol Homeopathic Hospital with 6,500 consecutive patients. In this study, carried out over a six-year period, $70 \%$ of patients reported an improvement in their health. ${ }^{5}$

Despite the article's claim that it is seeking to provide a summary of the science of homeopathy, it does no such thing. While it is true to say that scientists cannot yet explain the precise mechanism of action of homeopathic remedies, D. Shaw merely jumps on a bandwagon of dismissing homeopathy out of hand. There are many things that science cannot yet explain surely it is the job of scientists to seek to understand the mysterious, rather than trample it underfoot.

\section{Z. Dymitr}

Chairwoman, Society of Homeopaths

1. British Homeopathic Association. The Research Evidence Base for Homeopathy. www.britishhomeopathic.org/export/sites/bha site/research/ evidencesummary.pdf Accessed Dec 2010.

2. Witt C, Keil T, Selim D et al. Outcome and costs of homeopathic and conventional treatment strategies: a comparative cohort study in patients with chronic disorders. Complement Ther Med 2005; 13: 79-86.

3. Witt $\mathrm{C} M$, Bluth $\mathrm{M}$, Albrecht $\mathrm{H}$ et al. The in vitro evidence for an effect of high homeopathic potencies - a systematic review of the literature. Complement Ther Med 2007; 15: 128-138.

4. Endler P C, Heckmann C, Lauppert E et al. Themetamorphosis of amphibians and information of thyroxine. In Schulte J, Endler P C (eds). Fundamental research in ultra high dilution and homoeopathy. Dordrecht: Kluwer Academic Publishers, 1998.

5. Spence D, Thompson E, Barron S. Homeopathic treatment for chronic disease: a 6-year, universityhospital outpatient observational study. J Altern Complement Med 2005; 5: 793-798.

DOI: 10.1038/sj.bdj.2011.247

\section{LEARNING LESSONS}

Sir, we congratulate Davies and Bridgman (Br Dent $J$ 2011; 210: 59-61) for expressing so clearly that the traditional model of (oral) health education for children lacks evidence. Knowledge alone does not lead to significant behaviour change in adults, adolescents or children. However, this outdated and simplistic model of health education is still the basis for many oral health promotion activities worldwide, including many of 